\title{
Structural aspects of Alzheimer's disease immunotherapy targeted against amyloid-beta peptide
}

\author{
Cehlar $\mathrm{O}^{1}$, Skrabana $\mathrm{R}^{1}$, Revajova $\mathrm{V}^{2}$, Novak $\mathrm{M}^{1}$ \\ Institute of Neuroimmunology, Slovak Academy of Sciences, Bratislava, Slovakia. \\ ondrej.cehlar@savba.sk
}

\section{ABSTRACT}

Alzheimer's disease is the most prominent neurodegenerative disease and has no efficient therapies available so far. Immunotherapy against amyloid- $\beta(A \beta)$ peptide is one of the currently tested therapeutic approaches. Here we have reviewed the available structural knowledge about antibodies tested as passive anti-A $\beta$ immunotherapy in clinical trials. The therapeutic anti- $A \beta$ antibodies differ in their epitope specificity and in recognition and affinity to different $A \beta$ species present in vivo (Tab. 1, Fig. 1, Ref. 17). Text in PDF www.elis.sk. KEY WORDS: Alzheimer's disease, amyloid beta, immunotherapy, antibody-amyloid complex.

\section{Introduction}

Major histopathological hallmarks of Alzheimer's disease are senile plaques composed of amyloid- $\beta(\mathrm{A} \beta)$ peptide and neurofibrillary tangles composed of tau protein. The $3 \mathrm{D}$ structure of a stable polymorph of amyloid fiber composed from A $\beta 1-42$ peptide, the most toxic and aggregation-prone cleavage product of amyloid precursor protein, was recently determined by solid state NMR and is composed of two molecules per fibril layer that are forming a double-horseshoe-like cross- $\beta$-sheet entity $(1,2)$. However, it seems that the culprits of toxicity are rather the unstable $A \beta$ oligomers that are capable to disrupt cellular membranes by pore formation $(3,4)$.

One likely mechanism which the passive immunotherapy against $\mathrm{A} \beta$ peptide is based on is the peripheral sink phenomenon, where the peripherally administered antibodies bind circulating soluble $\mathrm{A} \beta$ species and change the $\mathrm{A} \beta$ concentration ratios between $\mathrm{CNS}$ and plasma. The gradient in $\mathrm{A} \beta$ concentration promotes its export from the brain and dissolution of amyloid plaques (5).

In this review, we summarize anti- $\mathrm{A} \beta$ antibodies with a publicly available structure, which have entered the clinical trials (Tab. 1), namely bapineuzumab, gantenerumab, crenezumab, solanezumab and ponezumab. Solanezumab and bapineuzumab did not improve clinical outcomes in patients with mild to moderate Alzheimer's disease. The publicly available data from Phase II studies for these antibodies indicate that neither of compounds produced a compelling evidence of drug-like behavior that would

${ }^{1}$ Institute of Neuroimmunology, Slovak Academy of Sciences, Bratislava, Slovakia, and ${ }^{2}$ The University of Veterinary Medicine and Pharmacy in Kosice, Slovakia

Address for correspondence: $\mathrm{O}$. Cehlar, Ing, $\mathrm{PhD}$, Institute of Neuroimmunology of SAS Dubravska cesta 9, SK-845 10 Bratislava, Slovakia. Phone: +421.2.54788100, Fax: +421.2 .54774276$

Acknowledgement: This work was supported by the VEGA grant No. 2/0177/15 and by EU structural funds ITMS 26240220008. justify their progression into phase III trials (17). It is considered that it may be an issue of treatment window and therefore the anti $\mathrm{A} \beta$ antibodies are further being examined in trials of treatment in at-risk asymptomatic individuals (Dominantly Inherited Alzheimer Network (DIAN) trial, Alzheimer Prevention Initiative (API) trial) (13). Clinical trials of ponezumab were also discontinued in association with Alzheimer's disease, and the antibody is now in phase II for cerebral amyloid angiopathy (www.AlzForum.org). The reviewed anti-A $\beta$ antibodies, crenezumab and gantenerumab, are in an ongoing phase III of clinical trials.

\section{Antibodies targeting the $\mathrm{N}$-terminus of $\mathrm{A} \beta$ peptide}

Bapineuzumab is an IgG1 antibody produced by humanization of parent murine antibody $3 \mathrm{D} 6$. The $\mathrm{K}_{\mathrm{D}}$ of bapineuzumab interaction measured with thermophoresis increases from $89 \mathrm{nM}$ measured with $\mathrm{A} \beta 1-40,151 \mathrm{nM}$ with $\mathrm{A} \beta 1-28$, to $4.5 \mu \mathrm{M}$ with $\mathrm{A} \beta$ 1-8 peptide, indicating that a longer peptide sequence is needed for full reactivity (6). Bapineuzumab captures $A \beta$ in a $3_{10}$ helical conformation stabilized by five intramolecular hydrogen bonds. The N-terminal amine of $A \beta$ is involved in hydrogen bonds with Glu3 $^{A B}$ side-chain carboxyls andAsp1 $1^{A \beta}$ binds to the bottom of bapineuzumab paratope groove, where its side-chain carboxyl makes hydrogen bond with Ser $100 \mathrm{~b}^{\mathrm{CDRH} 3}$ and side-chain nitrogen of Trp89 ${ }^{\text {CDRL3 }}$. A $\beta$ residues Glu3 and Arg5 form salt bridges with bapineuzumab residues Arg96 $6^{\text {CDRL3 }}$ and Asp27 $\mathrm{d}^{\mathrm{CDRL} 1}$, respectively. The guanidinium group of $\mathrm{Arg} 5^{\mathrm{A} \beta}$ side-chain $\pi$ stacks over the sidechain of Tyr $32^{\mathrm{CDRL} 1}$. The hydrophobic side-chain of Phe $4^{\mathrm{A} \beta}$ is buried and $\pi$ stacks against the side-chain of Tyr $95^{\mathrm{CDRH} 3}$. The structure of $A \beta$ in complex with bapineuzumab is similar to the TFE stabilized solution structures of $A \beta$ determined by NMR. The reactivity of bapineuzumab with plaques suggests the presence of this conformation also in dense $A \beta$ deposits with core cross- $\beta$ structure $(6$, 7). Interestingly, in the recent ssNMR structure of $A \beta 1-42$ fiber, $\mathrm{A} \beta$ residues 1-15 comprising the epitope of bapineuzumab are not 
Tab. 1. Summary of anti A $\beta$ antibodies with structures available in PDB that were tested in clinical trials.

\begin{tabular}{|c|c|c|c|c|c|c|}
\hline Antibody & PDB ID & Isotype & $\mathrm{A} \beta$ epitope & $\mathrm{A} \beta$ conformation & Binds to $A \beta$ species & Ref. \\
\hline Bapineuzumab & 4HIX & IgG1 & $1-6$ & $3_{10}$ helix & Plaques, soluble $\mathrm{A} \beta$ species & $(6)$ \\
\hline Gantenerumab & $5 \mathrm{CSZ}$ & IgG1 & $1-11$ & Extended coil with $\gamma$ turn & fibrils, oligomers, monomers & $(10)$ \\
\hline Crenezumab & $5 \mathrm{VZY}$ & IgG4 & $13-24$ & Extended coil with C-terminal turn & monomers, oligomers, fibrils and plaques & (11) \\
\hline Solanezumab & 4XXD & IgG1 & $16-26$ & Extended coil with C-terminal $3_{10}$ helix & Monomers & (13) \\
\hline Ponezumab & 3U0T & $\begin{array}{l}\text { IgG2 with two Fc } \\
\text { mutations (effectorless) }\end{array}$ & $30-40$ & Extended coil with $4 \beta$-turns & A $\beta 1-40$, plaques & $(15)$ \\
\hline
\end{tabular}

tightly bound to the fiber core (2). It has been noted that antibodies against the $3_{10}$ helical conformation of $\mathrm{A} \beta$ peptide are raised by immunization of mice with short $\mathrm{N}$-terminal $\mathrm{A} \beta$ peptide $(\mathrm{A} \beta 1-7$ conjugated to KLH in case of 3D6 antibody), whereas immunization with $A \beta 1-28, A \beta 1-42, A \beta$ fibrils or protofibrils produces antibodies recognizing extended $\mathrm{N}$-terminal $\mathrm{A} \beta$ conformation (antibodies 12A11, 12B4, 10D5, PFA1/PFA2, $\left.\mathrm{WO}_{2}\right)(8,9)$. The antibody $\mathrm{C} 706$ generated after immunization with $\mathrm{A} \beta 1-5$ binds $\mathrm{A} \beta$ $\mathrm{N}$-terminus in a somewhat distorted manner, as well as with $3_{10}$ helical conformation, and approaches $\mathrm{A} \beta$ from a different side (key epitope residues are $\mathrm{Arg} 5^{\mathrm{A} \beta}$ and His $6^{\mathrm{A} \beta}$ ) (9). It can be concluded that the length of $A \beta$ fragment modulates the preferred conformation of its N-terminus in the conformational ensemble of free peptide.

Gantenerumab was derived from a synthetic human combinatorial antibody library based on phage display. The epitope mapping using overlapping $A \beta$ decapeptides has revealed two discontinuous regions of recognition. The strongest one was the $\mathrm{N}$-terminal decapeptide ${ }^{3}$ EFRHDSGYEV ${ }^{12}$ and the other was a central decapeptide ${ }^{18}$ VFFAEDVGSN ${ }^{27}$. SPR revealed $K_{D}$ values of $0.6 \mathrm{nM}, 1.2 \mathrm{nM}$, and $17 \mathrm{nM}$ for fibrillar, oligomeric and monomeric A $\beta 1-40$, respectively, showing a preference for highmolecular structures. In structural studies, the gantenerumab Fab fragments were co-crystallized with $A \beta 1-11$ and $A \beta 3-11$ peptides. A $\beta$ 1-11 peptide binds in an extended conformation in the groove defined by CDRs H1, H2, H3, and L3. First three aminoacids of $\mathrm{A} \beta$ peptide interact with the antibody mainly through their mainchain carbonyl oxygen atoms. The side-chain of Phe $4^{\mathrm{A} \beta}$ is deeply buried in a hydrophobic pocket anchoring the $A \beta$ chain. The side-chain of $\operatorname{Arg} 5^{\mathrm{A} \beta}$ is stacked from one side by three antibody tyrosines. The N-terminal part of $A \beta$ peptide is in the proximity of $\mathrm{N}$-acetylglucosamide moiety found at Asn $52^{\mathrm{CDRH} 2}$. Ser8 ${ }^{\mathrm{A} \beta}$ and Gly $9^{\mathrm{A} \beta}$ residues point away and do not interact with the antibody. They form a short $\gamma$-turn that is stabilized by a hydrogen bond between the main-chain carbonyl of Asp $7^{\mathrm{A} \beta}$ and main-chain nitrogen of Tyr $10^{A \beta}$. The orientation of $A \beta$ peptide with respect to antibody CDRs is flipped in the gantenerumab complex by $180^{\circ}$ when compared to antibodies recognizing the extended $\mathrm{N}$-terminal conformation of $\mathrm{A} \beta(8,10)$.

\section{Antibodies targeting the mid-region of $A \beta$}

Crenezumab is a humanized IgG4 antibody that binds multiple forms of $\mathrm{A} \beta$ - monomers, oligomers, fibrils and plaques. The SPRmeasured $\mathrm{K}_{\mathrm{D}}$ was revealed to have a ten times higher affinity for high-molecular forms, being $0.4-0.6 \mathrm{nM}$ and 3.0-5.0 nM for oligomeric and monomeric $\mathrm{A} \beta$ forms (peptide 11-28), respectively (11).
Crenezumab was crystallized as synthetic CreneFab with mutations changing the heavy chain constant domain to $\mathrm{IgG} 1$ sequence. The aromatic side-chains of Phe $19^{\mathrm{A} \beta}$ and Phe $20^{\mathrm{A} \beta}$ are anchored to the bottom of the paratope groove by $\pi-\pi$ stacking interactions with Trp96 $6^{\mathrm{CDRL} 3}$ and His $34^{\mathrm{CDRL} 1}$. Charged side-chain of Asp23 ${ }^{\mathrm{A} \beta}$ forms hydrogen bonds with main-chain nitrogen of Gly $33^{\mathrm{CDRH}}$, whereas Ser52 $\mathrm{a}^{\mathrm{CDRH}} \mathrm{O} \gamma$ and Glu $22^{\mathrm{A} \beta}$ are engaged in water-mediated hydrogen bonding. Lys $16^{\mathrm{A} \beta}$ forms a salt bridge with Asp $101^{\mathrm{CDRH} 3}$ and is stacked between Tyr $32^{\mathrm{CDRH} 1}$ and Phe $27^{\mathrm{CDRH}}$. A non-canonical antibody-antigen interaction was observed between His $14^{\mathrm{A} \beta}$ sidechain and N-terminal amino group of heavy chain Glu1(11).

Solanezumab is a humanized monoclonal $\operatorname{IgG} 1$ antibody that recognizes soluble monomeric $A \beta$ with picomolar affinity and does not bind fibrillar $A \beta$ species. The epitope of solanezumab is partially overlapping the epitope of crenezumab. All CDRs are identical in length in solanezumab and crenezumab while L2, L3, and $\mathrm{H} 3$ are also identical in composition. Both antibodies therefore show cross reactivity with plasma proteins containing PhePhe dipeptide (14). The $\mathrm{K}_{\mathrm{D}}$ of solanezumab fully glycosylated at $\mathrm{N} 52^{\mathrm{CDRH} 2}$ was $4 \mathrm{pM}$, whereas the $\mathrm{K}_{\mathrm{D}}$ of a mutated unglycosylated variant drops to $0.8 \mathrm{pM}$. Nevertheless, these $\mathrm{K}_{\mathrm{D}}$ values are notcorrected for the avidity of bivalent antibody and therefore they are not directly comparable to other results (12). Solanezumab may bind $\mathrm{A} \beta$ monomers with the preference to adopt a helical conformation that was shown by NMR for $A \beta$ in helix promoting agents (13).

While bound to solanezumab, residues 16-18 of A $\beta$ adopt an extended coil conformation and residues following the Phe19 ${ }^{\mathrm{A}} \mathrm{B}_{-}$ Phe $20^{\mathrm{A} \beta}$ dipeptide, Ala2 $1^{\mathrm{A} \beta}$-Ser $26^{\mathrm{A} \beta}$, adopt a helical conformation. The conformation of central ${ }^{19} \mathrm{Phe}-\mathrm{Phe}-\mathrm{Ala}^{21} \mathrm{~A} \beta$ tripeptide in solanezumab and crenezumab complex structures resembles its conformation in ssNMR-determined A $\beta 1-42$ fibril and overlaps well with atom RMSD equal to $0.3 \AA$ (2).

In complex with solanezumab, Asp2 $3^{\mathrm{A} \beta}$ forms two hydrogen bonds with Ser33 ${ }^{\mathrm{CDRH} 1}$ ( $\mathrm{O} \gamma$ and main-chain nitrogen), which is compatible only with the helical $A \beta$ conformation (11). In contrast, crenezumab CDRH1, in position 33, occupies glycine, which is not able to make a side-chain hydrogen bond. $A \beta$ conformation recognized by crenezumab is therefore more open and relaxed in comparison with solanezumab, which can account for different reactivity of antibodies to fibrillar forms of $A \beta$.

The largest $A \beta$ side-chain difference between crenezumab and solanezumab-bound $\mathrm{A} \beta$ conformation is found for the side-chain of Glu22 $2^{A \beta}$. In complex with crenezumab, Glu22 ${ }^{A \beta}$ plunges into a volume surrounded by CDRs H1, H2, L3 and a water cluster. In contrast, this region is blocked in solanezumab by side-chains 
BAPINEUZUMAB

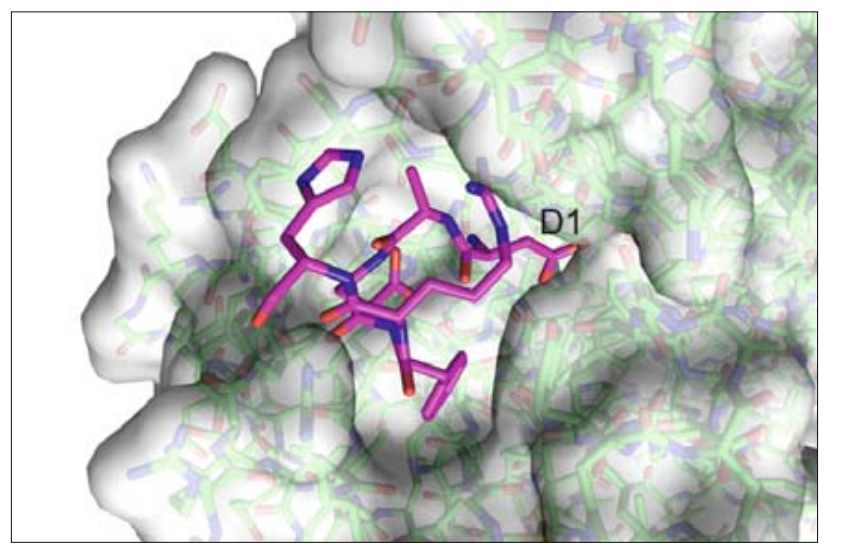

CRENEZUMAB

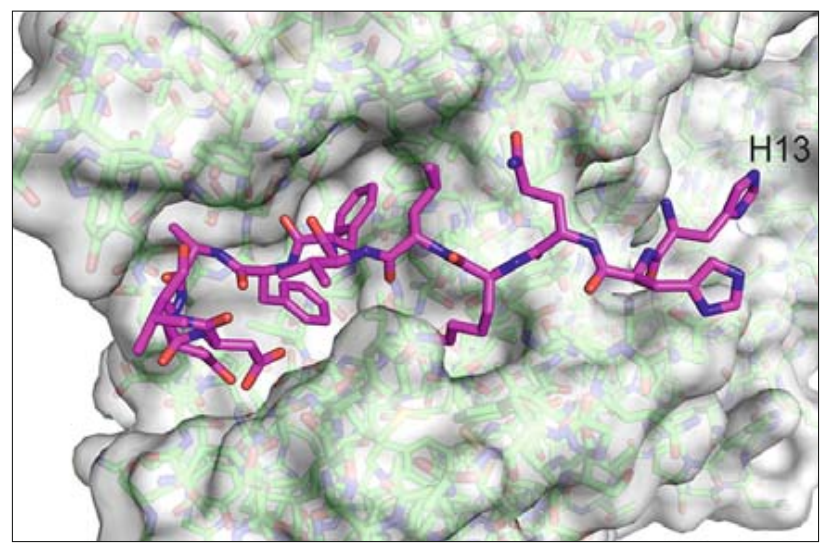

PONEZUMAB

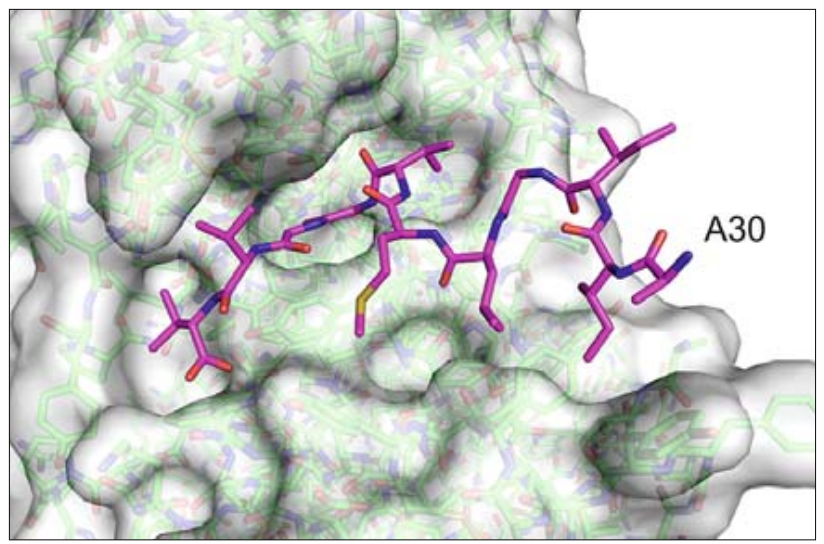

GANTENERUMAB

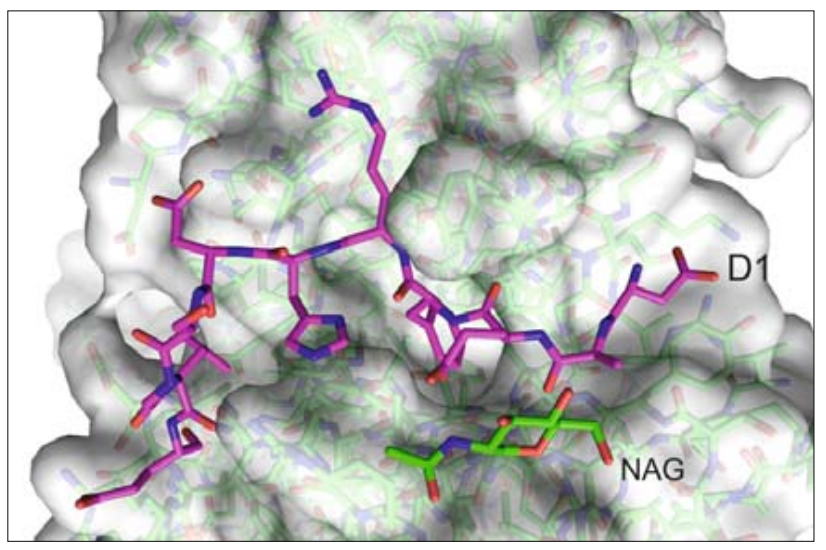

SOLANEZUMAB

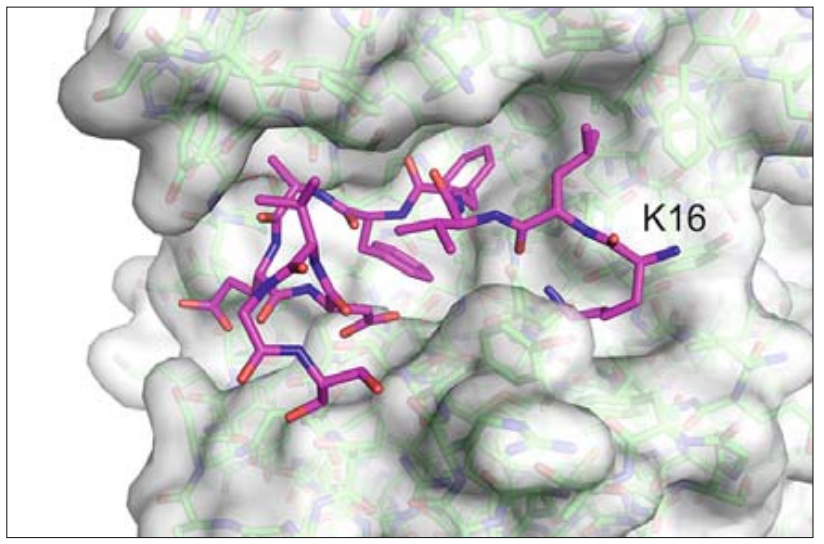

$\mathrm{A} \beta 1-42$ :

DAEFRHDSGY EVHHQKLVFF AEDVGSNKGA IIGLMVGGVV IA

Fig. 1. Structures of anti $A \beta$ antibodies. A $\beta$ peptide is shown as sticks with carbon atoms colored magenta while the first amino acid of $A \beta$ peptide observable in the complex is marked. Antibody paratopes are shown as a white transparent surface and sticks with carbon atoms colored green. $\mathrm{N}$-acetylglucosamide (NAG) present in gantenerumab is shown in sticks with green carbon atoms. Other atoms, namely oxygen, nitrogen and sulphur are colored red, blue, and yellow, respectively. Bottom right part of the figure shows the amino acid sequence of A $1-42$ peptide.

of Ser33 $3^{\mathrm{CDRH} 1}$ and Gln50 $0^{\mathrm{CDRH} 2}$, and Glu22 $2^{\mathrm{A} \beta}$ does not interact with solanezumab. However, the first putative helix stabilizing the hydrogen bond (between Phe $20^{\mathrm{A} \beta}$ backbone carbonyl and Asp23 ${ }^{\mathrm{A} \beta}$ backbone nitrogen) is present in both structures and is even shorter in the crenezumab complex structure.
Recently, Zhao et al. have investigated the different specificity of solanezumab and crenezumab by using computational methods, namely homology modeling, molecular docking and molecular dynamics simulations (14). They have simulated an interaction of solanezumab, CreneFab (used for crystallization) and 
crenezumab (homology modeled) with $\mathrm{A} \beta$ 12-28 monomer, and docked models of $A \beta$ 11-42 oligomer (5-mer) and fibril (16-mer) derived from ssNMR structure of $A \beta$. Their results have shown that crenezumab recognizes $\mathrm{N}$-terminally shifted hydrophilic and cationic epitope around residues 13-16 on different oligomeric $\mathrm{A} \beta$ forms, which was not observed for solanezumab. They also pointed out the influence of Fab constant domain on $\mathrm{A} \beta$ binding through entropy redistribution.

\section{Antibody targeting the free C-terminus of Aß1-40}

Ponezumab is a humanized monoclonal antibody that binds to $C$-terminus of $A \beta 1-40$. A $\beta 40$ residues 30 to 40 visible in the complex structure form of four $\beta$ turns $(31-34,33-36,35-38$, and 36-39). The C-terminal Val40 ${ }^{\mathrm{A} \beta}$ with its charged carboxyterminus interacts with ponezumab most extensively, forms nine interactions, and buries $35 \%$ of the total binding interface. The C-terminal carboxyl interacts with ponezumab residues Arg50 ${ }^{\mathrm{C}-}$ ${ }^{\text {DRH2 }}$ and Tyr9 $6^{\mathrm{CDRH} 3}$. The $\mathrm{N}$-terminal part of $\mathrm{A} \beta$ peptide (residues ${ }^{30} \mathrm{Ala}-\mathrm{Ile}-\mathrm{Il}{ }^{32}$ ) is stabilized by the constant domain of second $\mathrm{Fab}$ molecule present in asymmetric unit and probably does not correspond to the situation in solution. The SPR-measured $K_{D}$ of ponezumab binding to immobilized $\mathrm{A} \beta 17-40$ peptide was $0.3 \mathrm{nM}$ and it binds neither to $A \beta$ 17-42 peptide nor to $A \beta$ 17-40 peptide with amidated C-terminus (15).

\section{Conclusions and outlook}

The knowledge of detailed atomic resolution and complex structures of therapeutic antibodies with their targets is indispensable for correct elucidation of the therapeutic mode of action. The example of crenezumab and solanezumab complex structures shows how slight structural changes are manifested in different binding properties and selectivity. The structures of all mentioned antibody-A $\beta$ complexes are shown on Figure 1.

In phase III of clinical trials there is also a fully human IgG1 antibody named aducanumab. It is derived from healthy aged donors and its structure is not available. The antibody may bind with conformational epitope on $\mathrm{A} \beta$. However, $41 \%$ of patients receiving the highest tested dose of $10 \mathrm{mgkg}^{-1}$ of aducanumab have developed ARIA-E (amyloid-related imaging abnormalities such as vasogenic edema) abnormalities early in the course of treatment (16). A dose lowered due to the side effects may be too low to exhibit beneficial clinical outcomes in passive immunotherapy targeting $A \beta$ peptide.

\section{References}

1. Colvin MT et al. Atomic Resolution Structure of Monomorphic Abeta42 Amyloid Fibrils. J Amer Chem Soc 2016; 138 (30): 9663-9674.

2. Walti MA et al. Atomic-resolution structure of a disease-relevant A beta(1-42) amyloid fibril. Proc Nation Acad Sci USA 2016; 113 (34): E4976-E4984.

3. Do TD et al. Amyloid beta-Protein C-Terminal Fragments: Formation of Cylindrins and beta-Barrels. J Amer Chem Soc 2016; 138 (2): 549-557.

4. Bode DC, Baker MD, Viles JH. Ion Channel Formation by Amyloidbeta(42) Oligomers but Not Amyloid-beta(40) in Cellular Membranes. J Biol Chem 2017; 292 (4): 1404-1413.

5. Zhang Y, Lee DHS. Sink Hypothesis and Therapeutic Strategies for Attenuating A beta Levels. Neuroscientist 2011; 17 (2): 163-173.

6. Miles LA et al. Bapineuzumab captures the N-terminus of the Alzheimer's disease amyloid-beta peptide in a helical conformation. Scientific Reports, 2013, 3 .

7. Feinberg $\mathbf{H}$ et al. Crystal structure reveals conservation of amyloidbeta conformation recognized by 3D6 following humanization to bapineuzumab. Alzheimers Res Ther 2014; 6 (3).

8. Basi GS et al. Structural Correlates of Antibodies Associated with Acute Reversal of Amyloid beta-related Behavioral Deficits in a Mouse Model of Alzheimer Disease. J Biol Chem 2010; 285 (5): 3417-3427.

9. Teplyakov A, Obmolova G, Gilliland GL. A coiled conformation of amyloid-beta recognized by antibody C706. Alzheimers Res Ther 2017; 9 .

10. Bohrmann B et al. Gantenerumab: A Novel Human Anti-A beta Antibody Demonstrates Sustained Cerebral Amyloid-beta Binding and Elicits Cell-Mediated Removal of Human Amyloid-beta. J Alzheimers Dis 2012; 28 (1): 49-69.

11. Ultsch $M$ et al. Structure of Crenezumab Complex with A beta Shows Loss of beta-Hairpin. Scientific Reports, 2016, 6.

12. Watt AD et al. Do current therapeutic anti-A beta antibodies for Alzheimer's disease engage the target? Acta Neuropathol 2014; 127 (6): 803-810.

13. Crespi GAN et al. Molecular basis for mid-region amyloid-beta capture by leading Alzheimer's disease immunotherapies. Scientific Reports, 2015,5 .

14. Zhao J, Nussinov R, Ma BY. Mechanisms of recognition of amyloidbeta (A beta) monomer, oligomer, and fibril by homologous antibodies. $\mathrm{J}$ Biol Chem 2017; 292 (44): 18325-18343.

15. La Porte SL et al. Structural Basis of C-terminal beta-Amyloid Peptide Binding by the Antibody Ponezumab for the Treatment of Alzheimer's Disease. J Mol Biol 2012; 421 (4-5): 525-536.

16. Sevigny $\mathbf{J}$ et al. The antibody aducanumab reduces $A$ beta plaques in Alzheimer's disease. Nature 2016; 537 (7618): 50-56.

17. Gold M. Phase II clinical trials of anti-amyloid $\beta$ antibodies: When is enough, enough? Alzheimer's \& Dementia: Translat Res Clin Interv 2017; 3 (3): 402-409. 